University of South Carolina

Scholar Commons

2016

Developing a Risk Model to Target High-Risk Preventive Interventions for Sexual Assault Victimization Among Female U.S. Army Soldiers

Amy E. Street

Anthony J. Rosellini

Robert J. Ursano

Steven G. Heeringa

Eric D. Hill

See next page for additional authors

Follow this and additional works at: https://scholarcommons.sc.edu/man_facpub

Part of the Business Administration, Management, and Operations Commons

Publication Info

Published in Clinical Psychological Science, 2016, pages 939-956.

(C) The Author(s) 2016

This Article is brought to you by the Management Department at Scholar Commons. It has been accepted for inclusion in Faculty Publications by an authorized administrator of Scholar Commons. For more information, please contact digres@mailbox.sc.edu. 


\section{Author(s)}

Amy E. Street, Anthony J. Rosellini, Robert J. Ursano, Steven G. Heeringa, Eric D. Hill, John Monahan, James A. Naifeh, Maria V. Petukhova, Ben Y. Reis, Nancy A. Sampson, Paul D. Biese, Murray B. Stein, Alan M. Zaslavsky, and Ronald C. Kessler 


\title{
Developing a Risk Model to Target High-Risk Preventive Interventions for Sexual Assault Victimization Among Female U.S. Army Soldiers
}

Clinical Psychological Science 2016, Vol. 4(6) 939-956 (C) The Author(s) 2016 Reprints and permissions: sagepub.com/journalsPermissions.nav DOI: $10.1177 / 2167702616639532$ cpx.sagepub.com @SAGE

\author{
Amy E. Street ${ }^{1}$, Anthony J. Rosellini ${ }^{2}$, Robert J. Ursano ${ }^{3}$, \\ Steven G. Heeringa ${ }^{4}$, Eric D. Hill ${ }^{2}$, John Monahan ${ }^{5}$, \\ James A. Naifeh ${ }^{3}$, Maria V. Petukhova ${ }^{2}$, Ben Y. Reis ${ }^{6}$, \\ Nancy A. Sampson ${ }^{2}$, Paul D. Bliese ${ }^{7}$, Murray B. Stein ${ }^{8}$, \\ Alan M. Zaslavsky ${ }^{2}$, and Ronald C. Kessler ${ }^{2}$ \\ ${ }^{1}$ National Center for PTSD at VA Boston Healthcare System and Boston University School of Medicine, ${ }^{2}$ Harvard Medical \\ School, ${ }^{3}$ Uniformed Services University School of Medicine, ${ }^{4}$ University of Michigan, ${ }^{5}$ University of Virginia, ${ }^{6}$ Boston \\ Children's Hospital and Harvard Medical School, ${ }^{7}$ University of South Carolina, and ${ }^{8}$ University of California San Diego \\ and VA San Diego Healthcare System
}

\begin{abstract}
Sexual violence victimization is a significant problem among female U.S. military personnel. Preventive interventions for high-risk individuals might reduce prevalence but would require accurate targeting. We attempted to develop a targeting model for female Regular U.S. Army soldiers based on theoretically guided predictors abstracted from administrative data records. As administrative reports of sexual assault victimization are known to be incomplete, parallel machine learning models were developed to predict administratively recorded (in the population) and selfreported (in a representative survey) victimization. Capture-recapture methods were used to combine predictions across models. Key predictors included low status, crime involvement, and treated mental disorders. Area under the receiver operating characteristic curve was .83-.88. Between $33.7 \%$ and $63.2 \%$ of victimizations occurred among soldiers in the highest risk ventile (5\%). This high concentration of risk suggests that the models could be useful in targeting preventive interventions, although final determination would require careful weighing of intervention costs, effectiveness, and competing risks.
\end{abstract}

\section{Keywords}

machine learning, military sexual trauma, prediction model, rape, risk model, sexual assault

Received 12/18/15; Revision accepted 2/19/16

Sexual assault (i.e., forcible or attempted rape, sodomy, fondling/touching) is a significant problem in the U.S. military (Turchik \& Wilson, 2010). Recent survey data indicate that $4.9 \%$ of active-duty women experience sexual assault in a given 12-month period, with just under half of those experiences being penetrative assaults (i.e., rapes) and the remainder involving physical sexual contacts that did not include penetration (Morral et al., 2014). Because of demographic differences across samples and methodological inconsistencies across studies, it is difficult to make direct comparisons on sexual assault prevalence in the military versus the civilian population. However, there is evidence that active-duty women are more likely than demographically similar reserve component women (who spend less time in military settings) to experience sexual assault (Morral et al., 2015b). Sexual assault is known to be associated with significantly elevated subsequent levels of posttraumatic stress disorder, depression, and substance use disorders

Corresponding Author:

Ronald C. Kessler, Department of Health Care Policy, Harvard Medical School, 180 Longwood Ave., Boston, MA 02115, USA

E-mail: Kessler@hcp.med.harvard.edu 
(Kimerling, Gima, Smith, Street, \& Frayne, 2007; Street, Stafford, Mahan, \& Hendricks, 2008).

The Department of Defense (DoD) has responded to the problem of military sexual assault by creating an extensive sexual assault prevention program (Secretary of Defense, 2014). Consistent with widely accepted public health perspectives on sexual assault prevention, much of DoD's prevention program focuses on primary prevention efforts aimed at changing the behaviors of potential perpetrators (DeGue et al., 2012). However, evidence is mounting that there is also an important role for effective risk reduction programs aimed at the subset of women who have especially high risk of victimization (Senn et al., 2015). Although many sexual assault prevention programs involve relatively nonintensive universal interventions, successful large-scale prevention also requires more intensive selective interventions with highrisk individuals (Foster \& Jones, 2006; Golubnitschaja \& Costigliola, 2012). For such interventions to be costeffective in preventing outcomes with low base rates, though, methods need to be developed to target highrisk individuals for program implementation. Although actuarial risk prediction tools exist to identify individuals at high risk of sexual assault perpetration (Harris, Phenix, Hanson, \& Thornton, 2003; Quinsey, Harris, Rice, \& Cormier, 2006; Thornton et al., 2003) and intimate partner violence victimization (Campbell, Webster, \& Glass, 2009; Chan, 2012; Fengler \& Winkel, 2014), none exists to identify military personnel at high risk of sexual assault victimization.

One method for developing a risk model for military sexual assault victimization would be to select the predictors from the extensive series of administrative databases available for all military personnel. These databases were recently used successfully to develop prediction models for posthospitalization suicides (Kessler et al., 2015) and violent crime perpetration (Rosellini et al., 2016) in the U.S. Army. Models of this sort could have important practical applications because all variables identified in the risk profiles are available on a continuously updating basis for every military service member, allowing predictions of risk to be made at low cost and updated as necessary over time. The current report presents the results of an attempt to develop a prediction model of this sort for sexual assault victimization among female U.S. Army soldiers using predictors obtained from administrative databases.

A requirement for developing such a model is to impose some structure on the literally hundreds of thousands of administrative variables available for soldiers in order to make the task of analyzing the data tractable. We did this by reviewing the scientific literature on risk factors for sexual assault victimization and limiting the administrative variables considered in our analysis to those that operationalized the significant predictors in that literature. These predictors can be grouped into five categories, three of them having relevance to sexual assaults in any setting (i.e., sociodemographics, mental disorders, and prior experiences with crime) (Coxell, King, Mezey, \& Gordon, 1999; Franklin, Franklin, Nobles, \& Kercher, 2011; Harned, Ormerod, Palmieri, Collinsworth, \& Reed, 2002; Jewkes, Sen, \& Garcia-Moreno, 2002; Kimerling et al., 2007; Merrill et al., 1999; Sadler, Booth, Cook, \& Doebbeling, 2003; Tewksbury \& Mustaine, 2001; Turchik \& Wilson, 2010) and the other two being specific to the military (i.e., military career variables, military contextualenvironmental variables) (Kimerling et al., 2007; Sadler et al., 2003; Turchik \& Wilson, 2010).

The significant sociodemographic predictors of sexual assault victimization documented in the research literature include indicators of low sociocultural power, most notably young age, low socioeconomic status, and being nonmarried (Harned et al., 2002). These associations are consistent with the notion that sexual assault perpetrators often target women with low sociocultural power based on the assumption that these women will be both especially vulnerable to coercive behaviors and less likely than other women to report victimizations to authorities (Lisak \& Miller, 2002). In addition, young, unmarried women are more frequently exposed than other women to high-risk social situations (e.g., dates with unfamiliar partners, large parties involving alcohol; Krebs, Lindquist, Warner, Fisher, \& Martin, 2007).

A number of different mental disorders have been found to predict sexual assault victimization, including posttraumatic stress disorder, social phobia, and substance use disorder. Although there has been no research investigating the causal pathways involved in these associations, prior posttraumatic stress disorder (PTSD) has been interpreted as a risk marker for the wide range of risk factors that led to earlier victimization experiences resulting in PTSD (Orcutt, Erickson, \& Wolfe, 2002). It has also been noted that some PTSD symptoms (e.g., numbing, dissociation) might interfere with normal protective mechanisms like accurately attending to and responding to threat cues or effectively engaging in resistance behaviors (Risser, Hetzel-Riggin, Thomsen, \& McCanne, 2006). Symptoms of social phobia have also been hypothesized to increase risk of sexual assault victimization by reducing assertiveness in fending off sexual advances (Schry \& White, 2013). The associations of maladaptive alcohol and drug use with increased risk of sexual assault victimization have been hypothesized to operate through mechanisms involving increased exposure to high-risk situations, impulsivity, and impaired judgment $(H$. Littleton \& Ullman, 2013; Ullman, 2003).

There is also strong evidence in the literature that prior exposure to criminal victimization, particularly sexual 
victimization, is associated with increased risk of future sexual assault victimization. Although the preponderance of this evidence has focused on documenting associations between childhood sexual abuse and later sexual assault victimization in adolescence and adulthood (Lalor \& McElvaney, 2010), there is also evidence that women who experience sexual assault as adults are at increased risk of subsequent sexual assault victimization in both civilian and military settings (Littleton, Axsom, \& Grills-Taquechel, 2009; Sadler et al., 2003). Explanations for these associations have focused on stable individual differences in risk factors that might lead to repeat victimization as well as to effects of earlier victimization on subsequent interpersonal or sexual behaviors that increase risk for future victimization, such as increased number of consensual sexual partners, decreased sexual assertiveness, and acceptance of rape myths and sex-role stereotypes (Lalor \& McElvaney, 2010; Messman-Moore \& Long, 2000; Schry \& White, 2013).

Military career variables that have been found to predict female military sexual assault victimization include low power in the military hierarchy (e.g., low enlisted rank and few years in service) (Harned et al., 2002; Sadler et al., 2003) and deployment to a combat theatre (Leardmann et al., 2013). The latter association has been interpreted as reflecting increased exposure to perpetrators who are less concerned than they might otherwise be with the consequences of committing assaults because of being in high-stress war zone environments. Military contextual-environment variables, finally, that have been hypothesized to increase risk of female sexual assault victimization include a culture that tolerates sexual violence and encourages resolving interpersonal problems between peers rather than bringing them to the attention of superiors (Castro, Kintzle, Schuyler, Lucas, \& Warner, 2015). Norms of hypermasculinity and acceptance of violence have also been hypothesized to predispose to high rates of female military sexual assault victimization (Turchik \& Wilson, 2010). Although it has proven difficult to test these hypotheses empirically, it has been shown that risk of female sexual assault victimization is elevated in military units where officers engage in sexually harassing behaviors or tolerate the sexually harassing behaviors of others (Sadler et al., 2003).

We took advantage of a unique data source to select administrative indicators of the above predictors to develop a prediction model of sexual assault victimization among women in the U.S. Army: the Historical Administrative Data System (HADS) of the Army Study to Asses Risk and Resilience in Servicemembers (Army STARRS; Ursano et al., 2014). The HADS is a compilation of 38 different Army and DoD administrative data systems (see Table S1 in the Supplemental Material available online) organized into a single consolidated person-month database for each of the 975,057 Regular U.S. Army soldiers who were on active duty at any time between January 1, 2004 and December 31, 2009 (Kessler, Colpe et al., 2013). In addition to containing criminal justice records of reported sexual assault victimizations that we were able to use as our primary outcome, the HADS contains extensive data on sociodemographics, medical history, criminal justice history, military career experiences, and selected information on unit experiences for all active-duty soldiers during the years 2004 through 2009 .

Although administrative records of reported sexual assault victimization are the main outcome in our analysis, anonymous surveys of military personnel suggest that only a minority of military sexual assaults are reported to authorities (Mengeling, Booth, Torner, \& Sadler, 2014). These same surveys, which ask respondents not only if they were sexually assaulted but also whether they reported the assault to military authorities, also show that reported and unreported sexual assaults differ in important ways. For example, reported assaults are more likely than unreported sexual assaults to be perpetrated by strangers and to involve victim injuries and offender use of weapons (Wolitzky-Taylor et al., 2011). Based on this evidence, we not only developed a model to predict administratively reported sexual assaults in the total population of female soldiers in the HADS, but we also developed a parallel model using the same master set of HADS administrative variables to predict self-reported sexual assault victimization among the women who participated in the Army STARRS consolidated All-Army Study (AAS), a probability survey of all active-duty U.S. Army soldiers exclusive of those in Basic Combat Training (Ursano et al., 2014). As the predictors in the two models were drawn from the same administrative database, it was possible to use capture-recapture methods (Alho, 1990; Alho, Mulry, Wurdeman, \& Kim, 1993; Hook, Hsia, \& Regal, 2012; Sekar \& Deming, 1949) to combine predictions across the two models to arrive at a single consolidated estimate of individual-level risk of sexual assault victimization whether administratively recorded or self-reported.

\section{Methods \\ Samples}

The model to predict administratively recorded victimization was based on all female soldiers in the Regular Army (i.e., excluding the Army Reserve and National Guard) on active duty at any time between January 2004 and December 2009. We focused on first recorded instances of sexual assault victimization as the administratively recorded outcome. A discrete-time survival analysis framework with person-month as the unit of analysis was used to 
develop the model. Predictors that could change over time were coded as time-varying covariates (Willett \& Singer, 1993). The 153,250 female soldiers in the population during the years of study were in service for a total of 5,181,659 person-months over the study period. Person-months with incident administratively recorded sexual assault victimizations were coded 1 on the outcome variable, and all other person-months were coded 0 . Person-months were censored either at outcome occurrence, death, termination of active-duty service, or end of the study period, whichever came first. We focused on nonfamilial sexual assaults because only a small proportion of administratively recorded military sexual assaults involve perpetration by family members (Rock, 2013), and the predictors of nonfamilial and familial sexual victimization are known to be quite different from each other (Testa, VanZile-Tamsen, \& Livingston, 2007). Rather than carry out the analysis in the full population, control person-months were sampled using the logic of casecontrol analysis (Schlesselman, 1982) and weighted by the inverse of their probability of selection in the final analysis sample.

The model to predict self-reported sexual assault victimization was based on the subsample of female respondents in the Army STARRS consolidated AAS who consented to having their survey responses linked to their Army and DoD administrative records. The predictors used to develop the model were the same administrative predictors abstracted from the HADS as those in the analysis to predict administratively recorded victimization. However, these administrative variables were available to us only for the consolidated AAS sample, not the entire population of all soldiers, as of the time of the survey, which was administered in 2011-2012 to a representative sample of active-duty Regular Army soldiers exclusive of those in Basic Combat Training.

Although the AAS was administered throughout the world, we focused the model-building reported here on the subsample of 1,272 female AAS respondents consenting to record linkage who were stationed in the continental United States in large bases at the time of the survey. This restriction was due to the fact that these respondents were the only ones administered the computer-assisted version of the AAS, which allowed questions about the timing of recent exposure to traumatic events (one of which was sexual assault) to be asked with enough precision to match up with HADS administrative reports of victimization in the prior 12 months (or less) when not deployed as well as separately with administrative reports of victimization at any time during deployments that ended within the prior 12 months (even if they began more than 12 months ago). Other AAS respondents (i.e., those stationed either on small bases in the continental United States or outside of the continental
United States) completed a paper-and-pencil version of the survey that collected less precise information on timing of traumatic event exposure.

Given that AAS respondents were asked to self-report sexual assault victimization over the past 12 months of service (or, in the case of those who were deployed at any time in the past 12 months, separately to report victimizations that occurred during the recent deployment and during the part of the past 12 months when they were not deployed), the model to predict self-reported victimization was a person-level logistic model (rather than, as in the model to predict administratively recorded sexual assault victimization, a person-month model) in which the administrative predictors were time-invariant and were coded as of the month before the beginning of the recall period (i.e., either the month before the beginning of the most recent deployment to predict victimization during deployment, the last month of deployment to predict victimization after returning from deployment, or the 13 th month before the interview to predict victimization during the past 12 months among respondents who were not deployed at any time in the past 12 months).

AAS sampling began by selecting quarterly replicate samples of units or subunits in the eight quarters of 20112012 (i.e., January-March 2011, April-June 2011, . . . October-December 2012) with probabilities proportional to authorized unit strength excluding units of fewer than 30 soldiers (less than $\%$ of Army personnel). The sample was stratified by Army Command and location. An additional augmented AAS sample surveyed three Combat Brigades shortly before they deployed to Afghanistan and then again after their return from Afghanistan. Only the baseline survey in that panel sample is used here. On the day of the survey, all personnel in the selected unit attended an informed consent presentation explaining study purposes, confidentiality, and voluntary participation before being asked for written informed consent to complete a self-administered questionnaire, to link their administrative records to questionnaire responses, and to participate in future data collections. Identifying information needed to link administrative data to survey responses (e.g., name, social security number) was collected from respondents consenting to linkage and kept in a separate secure file. These recruitment, consent, and data-protection procedures were approved by the Human Subjects Committees of the Uniformed Services University of the Health Sciences for the Henry M. Jackson Foundation (the primary grantee), the Institute for Social Research at the University of Michigan (the organization collecting the data), and all other collaborating organizations.

The computerized version of the AAS survey was selfadministered using laptop computers in a group setting. The response rate in the target sample was $74.5 \%$. The 
remaining unit members included $15.0 \%$ nonresponse, much of it due to conflicting duty assignments, and 10.5\% incompletion after starting the survey, much of it due to logistical complications, such as units either arriving late or having to leave the sessions early, although some respondents needed more than the allotted time to complete the survey. Among AAS survey completers, 65.1\% provided data for administrative record linkage. Based on the American Association of Public Opinion Research Cooperation 1 (COOP1) calculation methods (American Association for Public Opinion Research, 2009), the overall survey completion-successful-linkage cooperation rate was $49.4 \%(.816 \times .931 \times .651)$. Additional details about the AAS survey design, samples, and informed consent procedures are reported elsewhere (Heeringa et al., 2013; Kessler, Colpe et al., 2013; Kessler, Heeringa et al., 2013).

As survey data were available for the $34.9 \%$ of survey completers who did not agree to administrative data linkage, a weighting adjustment was used to make the remaining $65.1 \%$ of survey completers (the latter group reported a slightly higher rate of sexual assault than the $34.9 \%$ who did not agree to administrative data linkage) equivalent to the total sample on the cross-classification of survey variables that most strongly differentiated the two subsamples. And as a restricted set of anonymized administrative data were made available to us for the population of all soldiers during the years of the consolidated AAS, we were also able to poststratify the weighted subsample of consolidated AAS respondents with linked administrative data to the cross-classification of those population distributions as well as to the distribution of Army Command, location, and the phase of the unit in the Army ARFORGEN (Army Force Generation; http:// www.forscom.army.mil/) cycle. We used these doubly weighted AAS data to build the model to predict selfreported sexual assault victimization. A detailed discussion of AAS weighting and poststratification is presented elsewhere (Kessler, Heeringa et al., 2013).

\section{Measures}

Administratively recorded victimization. Data from five criminal justice data systems (Sexual Assault Data Management System, Criminal Investigation Division Information Management System [CIMS]/Automated Criminal Investigation/Criminal Intelligence System, CIMS/Automated System Crime Record Center, Army Court Martial Information System, Centralized Operations Police Suite/Military Police Reporting System) were combined to identify the date, type, and judicial outcome of unrestricted nonfamilial administratively recorded sexual assault victimizations that occurred over the study period. Qualifying crimes of administratively recorded sexual assault victimization included rape (i.e., forcible vaginal intercourse), forcible sodomy (i.e., attempted or forcible oral or anal sex), and "other" sexual assault (i.e., attempted rape, fondling, indecent assault), as coded according to the Bureau of Justice Statistics National Corrections Reporting Program classification system (U.S. Department of Justice, 2009). In other words, our administratively recorded outcome did not include noncontact forms of unwanted sexual attention such as sexual harassment, exhibitionism, or Peeping Tom.

As mentioned above, unrestricted administrative records were used to define the outcome. However, sexual assault victims may also file restricted reports using the Victim Preference Reporting Statement (DD Form 2910). Restricted reports allow victims to receive medical treatment and counseling without triggering an official investigation of the assault, whereas unrestricted reports trigger an official investigation in addition to allowing the services available in restricted reporting. Victims may also decide to convert restricted reports to unrestricted reports at any time. As only unrestricted reporting data were made available to Army STARRS, it is important to note that a recent RAND survey found that among Army respondents who said they filed official reports, 51\% were unrestricted reports, $20 \%$ were restricted reports that were eventually converted to unrestricted reports, and 23\% were restricted reports (the remaining 6\% of Army respondents were not sure what type of report they filed; Morral et al., 2015b).

Self-reported victimization. The survey outcome, in comparison, was defined based on a question that asked respondents how many times they had been "sexually assaulted or raped." All respondents were asked this question as part of a longer checklist of traumatic experiences (TEs). It is important to note that use of this question may have failed to identify victims who would have qualified for our somewhat broader definition of administratively recorded victimization. Along these lines, although a large literature has focused on how the prevalence of sexual assault victimization varies depending on the phrasing of the self-report questions asked, time constraints precluded the AAS from asking additional behaviorally specific questions and/or using a two-stage approach for assessing sexual assault in the survey (Cook, Gidycz, Koss, \& Murphy, 2011; Fisher, 2009; Kruttschnitt, Kalsbeek, \& House, 2014).

Respondents who were not deployed in the 12 months before the AAS survey ( $n=1,056$ of the female AAS respondents considered here) were presented with a single checklist of TEs that might have occurred to them at any time in the past 12 months of service. Respondents who were deployed at any time in the past 12 months (the other $n=216$ female AAS respondents), in comparison, were presented with two lists: the first asking about 
TEs that occurred at any time during that deployment and the second asking about TEs that occurred at any time in the past 12 months of service other than during deployment. As the vast majority of the recent deployments of these respondents began more than 12 months before the survey, we treated these deployments as if they represented observations for 216 separate respondents that we combined with observations of times not deployed among all 1,272 respondents into a sample with a total of 1,488 observations. Not all of these 1,488 observations had a full 12 months of time at risk, as deployments varied between 2 and 25 months (mean = 10.1) and time in service in the past 12 months other than during deployment varied between 2 and 12 months (mean $=11.2)$. This variation was taken into consideration in the analysis by including months at risk as a control variable in the model. For purposes of the capture-recapture analysis (see below), we also constructed a yes-no variable for each of the 1,488 observations for whether there was an administrative record of the respondent having been sexually assaulted at any time during the months covered by the retrospective reporting period of that observation.

Administrative predictors. As reviewed earlier, the risk factors for military sexual assault victimization extracted from the 38 Army and DoD administrative data systems (see Table S1 in the Supplemental Material) in the larger HADS database were grouped into five categories. Given that our use of the HADS was opportunistic (i.e., we used administrative data collected for other purposes to operationalize constructs the measures were not originally designed to assess), we cast a wide net. Specifically, we selected 446 HADS variables to operationalize as many of the predictors as possible found in the literature, including 21 sociodemographic variables, 282 clinical variables (treated mental and physical disorders and medications), 66 variables for prior experience with crime (both victimization and perpetration), 38 variables defining military career experiences, and 39 military contextual variables (e.g., unit and leadership characteristics). We also included controls for year and season to adjust for the possibility of temporal variation. A complete description of predictors is available elsewhere (see Tables S2-S5 in the Supplemental Material).

\section{Analysis methods}

Building the models. Data analysis was carried out remotely by Harvard Medical School analysts on a secure server at the University of Michigan Army STARRS Data Coordination Center. De-identified analysis was approved by the Human Subjects Committees of the Uniformed Services University of the Health Sciences for the Henry
M. Jackson Foundation (the primary Army STARRS grantee), the University of Michigan, and Harvard Medical School. The governing Institutional Review Boards did not require informed consent from individual soldiers because HADS data were de-identified.

We followed a six-step analysis plan to predict each of the two outcomes:

1. We examined bivariate associations of predictors with victimization controlling for historical time either with a discrete-time person-month survival model having a logistic link function (Willett \& Singer, 1993) for the administrative outcome or a person-level logistic model for the survey outcome, both using SAS PROC LOGISTIC (SAS Institute Inc., 2010).

2. We transformed the functional forms of significant bivariate associations involving nondichotomous predictors to capture substantively plausible nonlinearities.

3. We estimated multivariate associations among significant bivariate predictors in logistic models.

4. As multivariate coefficients were unstable, we used machine learning methods to build more stable models. We began this phase of the analysis by using 10 -fold cross-validated stepwise regression to select the optimal minimum number of predictors to maximize concentration of risk (the proportion of observed occurrences of the outcome) in the top ventile of risk (i.e., the $5 \%$ of cases with highest cross-validated predicted risk).

5. We then searched for stable interactions among predictors in the optimal stepwise model using the R-package RandomForests (Breiman, Cutler, Liaw, \& Wiener, 2014) and determined incremental improvement in fit by examining the topventile concentration of risk in final 10-fold crossvalidated stepwise regression models with and without the addition of the RandomForests predicted probability of the outcome.

6. We then estimated elastic net penalized regression models specifying that the model select the optimal number of predictors determined in the stepwise model in order to obtain the most stable set among this optimal minimum number of predictors (Zou \& Hastie, 2005) using the R-package glmnet (Friedman, Hastie, \& Tibshirani, 2010).

Once the final penalized models were estimated, we generated predicted probabilities of the outcome for each person-month (administrative outcome) or person (survey outcome) in the dataset and computed area under the receiver operating characteristic curve (AUC) to evaluate model prediction accuracy, collapsing 
individual-level predicted probabilities into 20 groups of equal frequency (ventiles) to calculate the distribution of within-ventile concentration of risk.

Combining individual-level predicted probabilities across models. We then used the logic of capturerecapture analysis (Alho, 1990; Alho et al., 1993; Sekar \& Deming, 1949) to illustrate how the predicted probabilities of victimization based on the two models could be combined into consolidated individual-level estimates for each female soldier in the Army for practical use of the models in risk targeting. Importantly, we used this approach to estimate the consolidated prevalence of sexual assault victimization, which included estimates of actual administratively recorded victimization in the population, self-reported victimization in the AAS survey, and victimizations that were unreported in both the administrative data and the survey. It is important to note, though, that this consolidated calculation was made only as an illustration of the potential value of the approach in future coordinated applications because Army STARRS was not designed to develop precise capture-recapture estimates and our data were consequently limited in three ways that made it impossible to develop a definitive consolidated prediction model. First, sexual assault victimization was assessed in the AAS using a much less precise definition than the one used to define administratively recorded victimization. Second, administratively recorded victimization was based solely on unrestricted reports of victimization. Third, the retrospective time period over which self-reported victimization was assessed in the AAS (November 2009 through June 2012) was different from the time period for which we were granted access by the Army to the HADS data (January 2004 through December 2009). As noted above, although we had administrative data for AAS respondents who provided signed informed consent for us to have these data, we were not granted access to individual-level administrative data for the entire population of soldiers on active duty beyond 2009. Population-level data of that sort would have been required for the same time period as when the AAS was carried out to adjust the AAS sample data for discrepancies with the population and to construct a practically useful consolidated risk model.

Once appropriately linked administrative and survey data were available, we used a four-step process to combine individual-level predicted probabilities of sexual assault victimization based on separate models predicting administratively recorded and self-reported victimization for each female soldier in the HADS database:

1. We began by building conditional models for selfreported victimization in the presence of $\left(p_{1}\right)$, and separately in the absence of $\left(p_{2}\right)$, administratively recorded victimization. In future applications, these models should be based on a much larger sample than the AAS to guarantee precise estimates and to ask about sexual assault victimization using the same definition as in the administrative records. In order to estimate these illustrative models, we needed to include in the models information about administratively recorded victimization over the time period covered in the survey to determine if the predictors (i.e., administrative variables available at the time point prior to the reporting period in the survey) differed significantly depending on the presence versus absence of administratively recorded victimization over the same reporting period as in the survey;

2. We then built a model for administratively recorded victimization $\left(p_{3}\right)$ in the total population. Note that future applications should do this for the same reporting period as in the survey using administrative predictors that were available as the time point prior to the beginning of the recall period. As noted above, this was not possible in our illustrative application due to the fact that the HADS data were available to us only for 2004 through 2009, whereas the AAS data were collected in 2011 and 2012.

3. We then generated individual-level estimates of $p_{1}$, $p_{2}$, and $p_{3}$ for each woman in the AAS database based on the coefficients in the above models and manipulated these estimates to generate predicted probabilities of having both administratively recorded and self-reported victimization $\left(a=p_{1} p_{3}\right)$, administratively recorded but not self-reported victimization $\left(b=\left[1-p_{1}{ }_{p_{3}}\right)\right.$, and self-reported but not administratively recorded victimization $\left(c=p_{2}\left[1-p_{3}\right]\right)$.

4. We then estimated individual-level probabilities of being a true sexual assault victim by combining estimates of $a, b$, and $c$ for each individual with an estimate of the probability of being a true sexual assault victim but both failing to report it in an unrestricted fashion to the authorities and failing to report it in the survey $(d)$. We estimated $d$ based on the conservative assumption that the probability of reporting the victimization in unrestricted fashion to authorities and the probability of reporting it in the survey are independent of each other, in which case the individual-level value of $d$ is equal to the individual-level values of $b c / a$ (Alho, 1990; Alho et al., 1993; Sekar \& Deming, 1949).

It is noteworthy that the assumption of independence in developing a consolidated estimate of individual-level probability of victimization by summing $a, b, c$, and $d$ at the individual level is conservative given that $(a)$ we 
considered it implausible that there would be a negative association (given observed covariates and experience of victimization) between reporting to authorities and reporting in the survey and (b) $d$ increases as the positive association between the two forms of reporting increases (Alho, 1990; Hook et al., 2012; Sekar \& Deming, 1949). The estimate is also conservative in that it excludes soldiers who had a 0 probability of either reporting to authorities or reporting in the survey. A standard error of the consolidated prevalence estimate (the mean of the sum of the individual-level estimates of $a, b, c$, and $d$ ) was obtained by simulation using the method of jackknife repeated replications (Wolter, 1985) based on a SAS (SAS Institute Inc., 2010) macro.

It is noteworthy that the assumption in the capturerecapture model that there might be some soldiers who reported to authorities but not in the survey contradicts the assumption typically made implicitly in anonymous surveys that there are no such individuals, in which case survey reports are taken as accurate reflections of true prevalence (Morral et al., 2015a) and information about bias in administrative reports is assumed to be obtained without bias by asking survey-reported victims about whether they also reported the victimization to authorities (Morral et al., 2015b). But this assumption could be incorrect. For example, some soldiers might believe that administrative reports would be confidential but that survey reports might not be confidential. Indeed, we document below that a substantial number of female sexual assault victims in the U.S. Army have exactly this type of reporting pattern, making it important to think through the logic of using linked administrative-survey data collection and capture-recapture data analysis in future studies of the prevalence and correlates of military sexual assault victimization.

\section{Results}

\section{Prevalence of sexual assault victimization}

Administratively recorded sexual assault victimization (i.e., rape, sodomy, attempted assault, fondling/touching) was reported without restriction by 4,252 women in the Regular Army from 2004 through 2009. Prevalence over that time period was $10.0 / 1,000$ person-years. Of all administratively recorded victims, $85.2 \%$ were women (see Table S6 in the Supplemental Material).

Prevalence of first administratively recorded sexual assault victimization among AAS women, in comparison, was $15.9 / 1,000$ person-years. The fact that this rate was higher than in the HADS presumably reflects the facts that the AAS was based on a sample rather than the population, that the AAS subsample considered here was limited to soldiers who had completed basic training and were stationed in the continental United States at the time of survey, and that the reporting period in the AAS was later than in the HADS.

Prevalence of self-reported sexual assault (i.e., based on reports of being "sexually assaulted or raped") among AAS women over the reporting period in the survey was 18.6/1,000 person-years. Although administratively recorded and self-reported victimization were strongly related to each other among AAS women (odds ration $(\mathrm{OR})=42.4,95 \%$ confidence interval $(\mathrm{CI})=[34.5,52.1])$, the association was far from perfect, with only $29.3 \%$ of the self-reported victimizations being recorded administratively and only $34.2 \%$ of administratively recorded victimizations being reported in the survey. Prevalence of either was 29.0/1,000 person-years.

The finding that close to two thirds of administratively recorded cases were not reported in the AAS survey is especially striking in light of the fact that, as noted in the introduction, previous research has for the most part assumed that anonymous survey reports are comprehensive-that is, that there are no victims who report to authorities but do not report in surveys. One possible explanation for this survey nonreporting is that these women experienced fondling/touching rather than rape, sodomy, or attempted assault and consequently did not consider themselves to qualify for what the survey described as being "sexually assaulted or raped." However, an investigation of more detailed HADS reports shows that this explanation is inadequate, as a substantial proportion of the women with administratively recorded sexual assault victimization who failed to self-report in the survey that they had been sexually assaulted or raped were classified in the HADS as having been victims of rape.

It is also worth recalling in this regard that the subset of AAS respondents considered here represent those who agreed for their surveys to be de-identified (i.e., for their identities to be known for purposes of record linkage and follow-up) rather than anonymous (i.e., for their identities not to be known). It is conceivable that survey reporting was more complete in the segment of the AAS sample that required survey responses to be anonymous. However, this possibility is indirectly inconsistent with the fact that comparison of these reports (results available on request) showed that rates of self-reported victimization was lower among anonymous than de-identified AAS respondents. It is possible, though, that this result occurred because survey respondents who agreed to administrative linkage gave self-reports more consistent with their prior administrative reports than did survey respondents who did not agree to administrative linkage due to the former respondents knowing that this consistency would be checked. 


\section{Building the separate models for administratively recorded and self- reported victimization}

Roughly two thirds (69.9\%) of the 446 administrative predictors had significant (.05 level, two-sided tests) univariate associations with administratively recorded victimization in the HADS and $33.3 \%$ with self-reported victimization in the AAS. (see Tables S7-S19 in the Supplemental Material). In the unrestricted stepwise models, 81 of these predictors entered at the .05 level in the HADS and 56 in the AAS, 19 (HADS) and 8 (AAS) of which remained in the cross-validated models. AUC and top-ventile concentration of risk did not improve when summary variables for RandomForests predictors were added to the predictor set in the HADS (see Table S20 in the Supplemental Material). The sample size was too small for RandomForests to be estimated in the AAS.

Top-ventile concentration of risk was very similar in the optimal penalized and unpenalized models $(33.6 \%$ in both models in the HADS; $60.8 \%-63.7 \%$ in the AAS).
(Figure 1). AUC of the penalized and unpenalized models was also very similar (.83 in both models in the HADS; .88 in both models in the AAS). It is important to note, though, that we included a dichotomy indicating whether the respondent had administratively recorded victimization as one of the predictors of self-reported victimization in the AAS model. We would expect AUC of the model to be inflated due to that predictor being included in the model. It is consequently noteworthy that the AUC of the AAS model was .84 when calculation of AUC was limited to the 1,458 cases out of the 1,488 in the total sample in which there was no administratively recorded victimization over the recall period. Top-ventile concentration of risk in that subsample was $71.1 \%$ in the unpenalized model and $59.9 \%$ in the penalized model. Prevalence in the top ventile of predicted risk (i.e., positive predictive value) was 67.3 to 67.4 per 1,000 personyears in the penalized and unpenalized models in the HADS (6.7 times the total-sample prevalence) and 226.1 to 237.0 per 1,000 person-years in the AAS (12.2-12.7 times the total-sample prevalence).

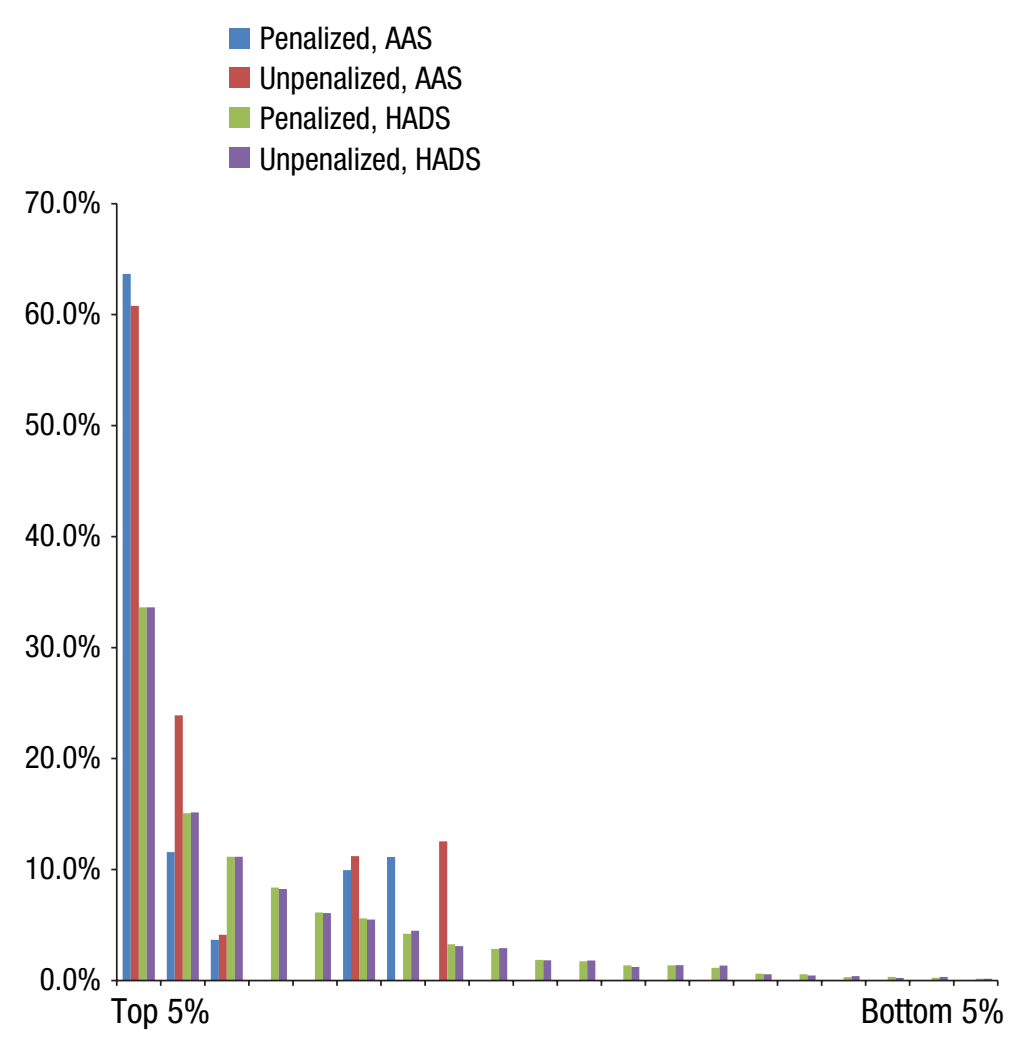

Fig. 1. Concentration of risk of major sexual crime victimization by ventile of predicted risk based on the final discrete-time survival models in the HADS (19 predictors $)$ and AAS ( 8 predictors) ${ }^{a}$ AAS $=$ All-Army Study; HADS $=$ Historical Administrative Data System.

${ }^{\mathrm{a}}$ Ventiles are 20 groups of person-months (HADS) or soldiers (AAS) of equal frequency dividing the total sample into equally sized groups defined by level of predicted victimization risk. 


\section{Model coefficients}

Five sociodemographic characteristics were significant predictors of administratively reported victimization in the HADS: young age (age 17-19 and 20-22), unmarried, non-Hispanic White, and less than high school education (Table 1). No sociodemographics were significant predictors of self-reported victimization in the AAS. One indicator of prior experience with crime in the HADS and two in the AAS were also significantly associated with elevated risk of victimization: previously being the victim of any crime in the past 24 months (HADS), previously being the perpetrator of a crime involving possession of an illegal substance (AAS), and the measure of administratively recorded sexual crime victimization over the same recall period as in the AAS (Table 2).

As one would expect from the very high bivariate OR reported above between administratively recorded and self-reported victimization, the OR of the former "predicting" the latter in the AAS was very high (130.9-32.0 in the unpenalized and penalized models, respectively). No significant interactions were found between this predictor and any of the other administrative predictors of selfreported victimization despite the fact that all such interactions were included in the variable set used to build the optimal elastic net model. These interactions were included in the initial variable set to allow for the possibility that the predictors of self-reported victimization differ depending on the presence versus absence of administratively recorded victimization. It is noteworthy that the small size of the AAS female sample resulted in low power to detect meaningful interactions of this type, though, which means that such interactions should not be assumed to be absent based on the AAS results.

Five clinical health factors in the HADS and six in the AAS were also significant predictors. Most of these focused on mental-health-related care. In the HADS, these were any outpatient visit for one or more visits for any mental disorder, three or more visits for any mental disorder, any inpatient hospitalizations for PTSD, visit for an injury/poisoning, and any visit for a physical-related diagnosis. The AAS variables were all for a 12-month retrospective time period and included two counts of outpatient visits (for injury/poisoning and traumatic stress), three measures of number of prescriptions (for benzodiazepines, other sedatives/hypnotics, and medications used primarily for migraine therapy), and a dichotomy for any prescription for a short-acting narcotic analgesic. No other predictors were significant in the AAS, but a number of military career variables were significant in the HADS. Two involved operational commands and another six, all associated with elevated risk of victimization, pertained to early career stage (junior-intermediate enlisted rank; 0-2 years in service). Finally, one military contextual predictor, number of different duty units over the past 12 months, was associated with significantly elevated risk.

\section{Sensitivity of results}

As the AAS sample was so small, no attempt was made to carry out internal validation of model results. This kind of validation was possible, though, for the HADS due its much larger size. As the HADS model was designed to predict victimization this month, prediction accuracy over longer time periods was evaluated by calculating average top-ventile concentration of risk for all possible 1-, 6-, and 12-month follow-up periods from January 2004 through January 2009 and in 20-month and 30-month intervals. (We excluded February-December 2009 because we did not have 12 months of follow-up data after these months.) Although average top-ventile estimates of concentration of risk were highest over 1-month periods $(26.4 \%-32.8 \%)$, they remained elevated over 6-month (23.7\%-27.8\%), and 12-month (21.4\%-24.2\%) periods and were consistent across the five 20-month and 30-month time intervals (see Table S21 in the Supplemental Material)

Although short time in service and early career stage were strong predictors of elevated victimization risk in the HADS, the failure of RandomForests to improve fit means that no interactions were found between time in service and other predictors. This might have been because we lacked adequate statistical power to detect these interactions, though, due to the high proportion of victimizations occurring in the first years of service. We evaluated this possibility by examining top-ventile concentration of risk in the HADS within subgroups defined by time in service (Table 3). Unsurprisingly, the proportion of soldiers in the top ventile of predicted risk varied inversely with time in service $\left(\chi_{5}^{2}=2,884.5, p<.001\right)$. However, when we recalibrated cut points to focus on the top ventile of predicted risk within each time in service subsample, the association between time in service and top-ventile concentration of risk became much smaller among $\left(\chi^{2}{ }_{7}=15.0, p=.040\right)$.

Although the association of time in service with topventile $C R$ decreased when ventiles were defined within time in service subsamples, the association of time in service with top-ventile positive predictive value increased. When the top ventile of predicted risk was defined without restriction, top-ventile positive predictive value ranged between $73.5 / 1,000$ person-years in the first year of service (when $23.8 \%$ of female soldiers were included in the top ventile and top-ventile concentration of risk was 57.1\%) and 0.0/1,000 person-years after 10 years of service (when $0.0 \%$ of female soldiers were included in the top ventile). When the top ventile was 
Table 1. Coefficients (Odds Ratios) From the Final Penalized and Unpenalized Survival Models Predicting First Administratively Reported Nonfamilial Major Sexual Crime Victimization Among Women in the HADS (2004-2009) ${ }^{\mathrm{a}}$

\begin{tabular}{|c|c|c|c|c|c|c|}
\hline & \multicolumn{3}{|c|}{ Penalized } & \multicolumn{3}{|c|}{ Unpenalized } \\
\hline & $\%$ & $(S E)$ & OR & OR & {$[95 \% \mathrm{CI}]$} & $\mathrm{VIF}^{\mathrm{b}}$ \\
\hline \multicolumn{7}{|l|}{ I. Sociodemographics } \\
\hline Age, 17-19 & 8.1 & $(0.1)$ & 2.1 & 2.0 & {$[1.9,2.2]$} & 1.6 \\
\hline Age, $20-22$ & 20.2 & $(0.2)$ & 1.5 & 1.5 & {$[1.4,1.7]$} & 1.4 \\
\hline Marital status, not currently married & 60.6 & $(0.2)$ & 1.3 & 1.3 & {$[1.3,1.5]$} & 1.1 \\
\hline Race/ethnicity, non-Hispanic White & 42.7 & $(0.2)$ & 1.9 & 1.9 & {$[1.8,2.0]$} & 1.1 \\
\hline Education, less than high school & 6.7 & $(0.1)$ & 1.4 & 1.4 & {$[1.3,1.5]$} & 1.1 \\
\hline \multicolumn{7}{|l|}{ II. Prior crime } \\
\hline Victim of any crime (past 24 months) & 5.6 & $(0.1)$ & 1.6 & 1.6 & {$[1.5,1.8]$} & 1.0 \\
\hline \multicolumn{7}{|l|}{ III. Clinical factors } \\
\hline Injury and poisoning, any outpatient visits (past 12 months) & 18.0 & $(0.2)$ & 1.3 & 1.3 & {$[1.2,1.4]$} & 1.1 \\
\hline Any mental diagnosis, $3+$ days with outpatient visits (past 12 months) & 6.6 & $(0.1)$ & 1.3 & 1.3 & {$[1.1,1.4]$} & 1.1 \\
\hline Any mental health diagnosis, any outpatient visits (past 12 months) & 40.3 & $(0.2)$ & 1.4 & 1.4 & {$[1.3,1.5]$} & 1.2 \\
\hline Any physical-related diagnosis, any outpatient visits (past 12 months) & 67.5 & $(0.2)$ & 1.3 & 1.3 & {$[1.2,1.4]$} & 1.1 \\
\hline PTSD, any inpatient hospitalizations (past 12 months) & 0.1 & $(0.0)$ & 3.9 & 3.9 & {$[2.5,6.1]$} & 1.0 \\
\hline \multicolumn{7}{|l|}{ IV. Military career } \\
\hline Rank junior enlisted (E1-E4) & 47.4 & $(0.2)$ & 5.7 & 6.6 & {$[5.4,8.0]$} & 2.3 \\
\hline Rank intermediate enlisted (E5-E6) & 25.9 & $(0.2)$ & 2.6 & 3.1 & {$[2.5,3.8]$} & 1.6 \\
\hline Years in service, 1 or less & 14.4 & $(0.2)$ & 2.5 & 2.6 & {$[2.3,2.8]$} & 1.9 \\
\hline Years in service, $1-2$ & 11.8 & $(0.1)$ & 1.6 & 1.6 & {$[1.5,1.8]$} & 1.4 \\
\hline \multicolumn{7}{|l|}{ V. Military context } \\
\hline Number of different duty units over past 12 months ${ }^{c}$ & 1.7 & $(0.0)$ & 1.3 & 1.3 & {$[1.2,1.3]$} & 1.2 \\
\hline
\end{tabular}

Note: 95\% CI = 95\% confidence interval; HADS = Historical Administrative Data System; OR = odds ratio; PTSD = posttraumatic stress disorder; VIF = variance inflation factor.

${ }^{a}$ All predictors shown here are significant at the .05 level (two-sided test) in the unpenalized model. Predictors were selected in the elastic net model based on internal cross-validation rather than significance tests, which is why no significance tests are presented for the penalized model ORs. The mixing model parameter $(\alpha)$ in the elastic net model was set to 0.5 based on the empirical finding that this was the value that maximized concentration of risk in the $5 \%$ of the sample with highest predicted risk. The analysis sample included all person-months with the outcome plus a probability sample of all other person-months in the population (total case-control sample of 113,592 person-month). All records in the control sample were weighted by the inverse of the probability of selection. One time control variable was selected by the elastic net model but is are not shown here. Two operational command variables stepped into the model but are not shown here.

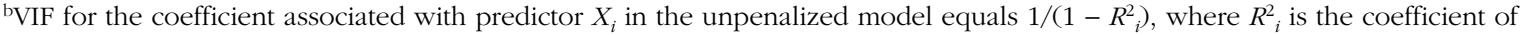
determination of a logistic regression equation in which $X_{i}$ is the dependent variable and all the other predictors in the model are included as predictors of $X_{i}$. VIF $\geq 5.0$ is typically considered an indicator of meaningful multicollinearity. The results reported here show that multicollinearity was not a problem in the unpenalized model despite the fact that the optimal mixing model parameter in the elastic net model used to select the predictors was $\alpha=0.5$

"This was coded 1 through 4 ( $1=$ one unit, $2=$ two units, $3=$ three units, and $4=$ four or more units). The value reported in the percentage columns reflects the average number of different duty units in the total sample based on that truncated coding scheme.

defined within time in service subgroups, in comparison, top-ventile positive predictive value ranged between $126.9 / 1,000$ person-years in the first year of service (when top-ventile concentration of risk was 20.5\%) and $1.2 / 1,000$ person-years after $20+$ years of service (when top-ventile concentration of risk was $12.5 \%$ ).

\section{Combining estimates across models}

The four-step process described above in the section on analysis methods was used to generate consolidated individual-level estimates of victimization for the 1,488 observations in the AAS. We imputed individual-level predicted probabilities of administratively recorded victimization in the AAS for that purpose by applying the coefficients from the HADS model to make initial estimates and then calibrating those estimates to make the sum of predicted probabilities equal the observed weighted proportion of respondents with administratively recorded victimization over the reporting period of the survey. Given that the model for self-reported victimization included administratively recorded victimization as one of the predictors, we were able to estimate individual-level predicted probabilities of self-reported 
Table 2. Coefficients (Odds Ratios) From the Final Penalized and Unpenalized Logistic Regression Models Predicting SelfReported Sexual Assault Victimization Among Women in the Selected AAS Subsample (2009-2012) ${ }^{\mathrm{a}}$

\begin{tabular}{|c|c|c|c|c|c|c|}
\hline & \multicolumn{3}{|c|}{ Penalized } & \multicolumn{3}{|c|}{ Unpenalized } \\
\hline \multicolumn{7}{|l|}{ I. Prior crime } \\
\hline Administratively recorded sexual crime victimization (not time-lagged) & 1.5 & $(0.3)$ & 32.0 & $130.9^{*}$ & {$[101.2,169.2]$} & 1.0 \\
\hline Perpetrator of illegal drug possession crime (past 12 months) & 0.1 & $(0.1)$ & 140.4 & $3,226.1^{*}$ & {$[1,102.0,9,443.5]$} & 1.0 \\
\hline \multicolumn{7}{|l|}{ II. Clinical factors } \\
\hline Injury/poisoning & 16.1 & $(1.3)$ & 1.3 & 2.7 & {$[2.3,3.2]$} & 1.1 \\
\hline \multicolumn{7}{|l|}{ Number of prescriptions (past 12 months) of... ${ }^{c}$} \\
\hline Benzodiazepines & 5.5 & $(1.0)$ & 1.2 & 1.4 & {$[1.2,1.6]$} & 1.1 \\
\hline Other sedatives/hypnotics & 5.6 & $(0.8)$ & 1.3 & 1.6 & {$[1.4,1.8]$} & 1.1 \\
\hline Medications to treat migraine & 1.4 & $(0.4)$ & 1.8 & 2.2 & {$[1.8,2.6]$} & 1.0 \\
\hline
\end{tabular}

Note: 95\% CI = 95\% confidence interval; AAS = All-Army Study; OR = odds ratio; VIF = variance inflation factor.

${ }^{a}$ All predictors shown here were significant at the .05 level (two-sided test) in univariate models, but only two are significant in the unpenalized logistic model. Variable selection in the elastic net model was based on internal cross-validation rather than significance tests, which accounts for why no significance tests are presented for the penalized model ORs and why predictors were included in the final model that were judged to be insignificant based on logistic regression model confidence intervals. The mixing model parameter $(\alpha)$ in the elastic net model was set to 0.9 based on the empirical finding that this was the value that maximized concentration of risk in the $5 \%$ of the sample with highest predicted risk. The data were doubly weighted to adjust for differences in the survey characteristics of AAS respondents who did versus did not agree to have their Army and DoD administrative records linked to their survey responses (Weight 1) and to poststratify the weighted AAS respondents who agreed to record linkage to match the cross-classification of selected de-identified population-level administrative variables that were provided to us by the Army for this purpose. Confidence intervals in the unpenalized model were calculated using the design-based method of jackknife repeated replications to take these weights into consideration along with the effects of the clustering of observations.

bVIF for the coefficient associated with predictor $X_{i}$ in the above equation equals $1 /\left(1-R_{i}^{2}\right)$, where $R_{i}^{2}$ is the coefficient of determination of a regression equation in which $X_{i}$ is the dependent variable and all the other predictors in the model are included as predictors of $X_{i}$. VIF $\geq 5.0$ is typically considered an indicator of meaningful multicollinearity.

'These were coded 0 through 4 ( $0=$ no visits, $1=1-2$ visits, $2=3-5$ visits, $3=6-10,4=11+$ visits $)$. The value reported in the percentage column reflects the proportion of the sample with one or more visits or prescriptions in the past 12 months.

victimization separately in the presence and absence of administratively recorded victimization directly from the AAS model coefficients by applying the individual-level predicted probability of administratively recorded victimization to the model.

We reported above that prevalence of sexual assault victimization among AAS women was 15.9/1,000 personyears administratively recorded and 18.6/1,000 personyears self-reported. The combined prevalence rate (i.e., administratively recorded and/or self-reported) was 29.0/1,000 person-years. Based on the above four-step process, we estimated conservatively that the prevalence of sexual assault unreported either to authorities or in the survey was 25.2/1,000 person-years, for an estimated total prevalence (standard error) of $54.2(10.8) / 1,000$ person-years. To the extent that the independence assumption needed to generate this estimate was accurate, it means that no more than $29.3 \%$ of all sexual assaults experienced by these women were reported to authorities, no more than $34.2 \%$ were self-reported in the survey, and no more than $46.5 \%$ were reported either to authorities or in the survey.

\section{Discussion}

Although considerable research has studied victimfocused predictors of sexual assault (Coxell et al., 1999; Franklin et al., 2011; Harned et al., 2002; Jewkes et al., 2002; Kimerling et al., 2007; Merrill et al., 1999; Sadler et al., 2003; Tewksbury \& Mustaine, 2001; Turchik \& Wilson, 2010), the current report presents the results of the first attempt to develop an actuarial risk model that could be used to identify women for interventions to prevent sexual assault victimization. Our findings that indicators of lower sociocultural (e.g., young age, low education, unmarried) and organizational (e.g., lower rank, more recently entered service, short time in the duty unit) power are significant predictors of administratively recorded military sexual assault victimization are consistent with previous studies (Harned et al., 2002), but we failed to find similar predictors of self-reported victimization. This inconsistency raises the possibility that soldiers with low sociocultural and organizational power are more likely than other soldiers to make administrative reports when they are sexually assaulted. This possibility 
Table 3. Prevalence per 1,000 Person-Years and Concentration of Risk (CR) in the Top Ventile (Both Overall and Within Time in Service Subsamples) of Observations With Highest Predicted Risk of First Administratively Recorded Nonfamilial Major Sexual Assault Victimization by Time in Service Among Female Regular Army Soldiers in the Army STARRS 2004-2009 HADS ${ }^{\mathrm{a}}$

\begin{tabular}{|c|c|c|c|c|c|c|c|c|c|c|}
\hline \multirow{3}{*}{$\begin{array}{l}\text { Years in } \\
\text { service }\end{array}$} & \multicolumn{6}{|c|}{ Overall ventiles with highest predicted risk } & \multicolumn{4}{|c|}{$\begin{array}{l}\text { Within time-in-service ventiles } \\
\text { with highest predicted risk }\end{array}$} \\
\hline & \multicolumn{2}{|c|}{$\begin{array}{c}\text { Prevalence/1,000 } \\
\text { person-years }\end{array}$} & \multicolumn{2}{|c|}{ Within-row CR } & \multicolumn{2}{|c|}{$\begin{array}{l}\text { Proportion of person- } \\
\text { months in top ventile }\end{array}$} & \multicolumn{2}{|c|}{$\begin{array}{l}\text { Prevalence } / 1,000 \\
\text { person-years }\end{array}$} & \multicolumn{2}{|c|}{ Within-row CR } \\
\hline & Est & $(S E)$ & Est & $(S E)$ & $\%$ & $(S E)$ & Est & $(S E)$ & Est & $(S E)$ \\
\hline $0-1$ & 73.5 & 2.8 & 57.1 & 1.1 & 23.8 & 0.5 & 126.9 & 8.9 & 20.5 & 0.9 \\
\hline $1-2$ & 55.1 & 3.6 & 31.9 & 1.4 & 12.0 & 0.4 & 67.6 & 6.4 & 16.4 & 1.1 \\
\hline $2-3$ & 50.5 & 12.7 & 4.5 & 0.9 & 1.0 & 0.1 & 37.8 & 4.7 & 17.6 & 1.7 \\
\hline $3-4$ & 45.0 & 19.4 & 2.6 & 1.0 & 0.4 & 0.1 & 21.5 & 3.6 & 15.7 & 2.2 \\
\hline $4-5$ & 19.8 & 15.3 & 1.1 & 0.8 & 0.3 & 0.1 & 18.6 & 3.8 & 15.5 & 2.7 \\
\hline 5-10 & 27.1 & 31.1 & 0.3 & 0.3 & 0.0 & 0.0 & 13.6 & 1.8 & 20.1 & 2.3 \\
\hline 10-20 & - $^{c}$ & $-^{c}$ & $-^{c}$ & $-^{c}$ & $-^{c}$ & $-^{c}$ & 5.5 & 1.1 & 26.6 & 4.6 \\
\hline $20+$ & $-^{c}$ & $-^{c}$ & $-^{c}$ & $-^{c}$ & $-^{c}$ & $-^{c}$ & 1.2 & 1.2 & 12.5 & 11.7 \\
\hline Total & 67.3 & 2.2 & 33.6 & 0.7 & 5.0 & 0.1 & 37.6 & 1.5 & 18.7 & 0.6 \\
\hline$\chi_{5-7}^{2}$ & $21.5^{*}$ & & $1631.4^{*}$ & & $2884.5^{*}$ & & $435.3^{*}$ & & $15.0^{*}$ & \\
\hline
\end{tabular}

Note: HADS $=$ Historical Administrative Data System; STARRS $=$ Study to Asses Risk and Resilience in Servicemembers. *Significant at the .05 level, two-sided test.

${ }^{a}$ Estimates are based on the coefficients from the total sample penalized models.

${ }^{b}$ Concentration of risk ventiles were reclassified independently within each time in service group so the top ventile of predicted risk includes 5\% of the person-months within each time in service category.

'There were zero person-months in the overall top ventile of predicted risk for women with $10+$ years in service. A five degree of freedom $\chi^{2}$ test was used to examine variation in these rates by time in service.

is consistent with independent survey data indicating that, among military personnel who report in a survey that they experienced sexual assault, junior enlisted personnel are most likely and senior officers are least likely to say that they made an administrative report of this event (Morral et al., 2015a). This might mean that seniority brings with it increased concerns about potential career-damaging retaliation of such reports, a commonly described barrier to sexual assault reporting (Morral et al., 2015b).

The finding in both of our models that prior involvement in crime is associated with elevated risk of sexual assault victimization is broadly consistent with previous research (Jewkes et al., 2002), although the indicator in the model to predict administratively recorded victimization was a measure of prior crime victimization, whereas the indicator in the model to predict self-reported victimization was a measure of prior crime perpetration. The finding in both models that treated mental disorders were associated with elevated risk of subsequent victimization is also consistent with a good deal of previous research (Littleton \& Ullman, 2013; Orcutt et al., 2002; Risser et al., 2006; Schry \& White, 2013; Ullman, 2003). The finding that treatment for injuries/poisonings was a risk factor, in comparison, has never before been examined, although it is noteworthy that we found this variable to be a significant predictor in the models for both administratively recorded and survey self-reported victimization. It is noteworthy that this injury/poisoning measure excluded most common military injuries (e.g., sprains, fractures) and focused on poisonings along with less common injuries (e.g., nerve injuries), raising the possibility that it reflects an influence of impulsive predispositions that lead both to injuries and to increased risk of sexual assault victimization.

The fit of our models was quite good (AUC $=.83$ for administratively recorded victimization; $\mathrm{AUC}=.88$ for self-reported victimization) compared to models developed to predict other types of violence (Fazel, Singh, Doll, \& Grann, 2012; Whittington et al., 2013; Yang, Wong, \& Coid, 2010). We also found that approximately one third of administratively reported victimizations and over $60 \%$ of self-reported victimizations occurred among the $5 \%$ of female soldiers with our highest predicted risk scores, although caution is needed in interpreting the very high value of the latter percentage because the AAS sample size was so small and this might have led to overfitting.

Despite this caution, the strong performance of both the HADS and AAS models argues that it might be feasible 
to carry out more definitive research designed explicitly to develop a consolidated set of models to predict overall sexual assault victimizations for female soldiers and use these models to determine which of these women should receive a high-risk preventive intervention. This survey would have to be based on a much larger and broadly representative sample of female soldiers than the AAS and would have to ask much more carefully worded questions about sexual assault victimization than the AAS to map closely to the official definition used in administrative records (Kruttschnitt et al., 2014). Administrative predictor variables would have to be available for the beginning of the same reporting period of this survey, and information on administratively recorded victimization (in the ideal case, both unrestricted and restricted reports) would have to be available over this same reporting period. With these data in hand, machine learning models like those developed here could be estimated and the coefficients from those models could be combined using the capturerecapture methods illustrated in our analysis to generate consolidated individual-level predicted probabilities of sexual assault victimization in subsequent cohorts. It would be important to update this model on a periodic basis (i.e., to carry out new periodic surveys and re-estimate models) both to capitalize on the opportunities presented by new Army and DoD data systems (e.g., the new Tailored Adaptive Personality Assessment System personality assessment questionnaire [Niebuhr et al., 2013], which was not available during the years of the HADS but is now administered to all Army) and to adjust for the possibility that some predictors of sexual assault victimization might change over time.

Before embarking on such an undertaking, though, it is important to ask whether female sexual assault victimization is sufficiently common even in the highest risk strata in our models to make selective intervention costeffective. The answer depends in large part on the strength of the intervention. There is evidence that fairly intensive victim-focused interventions can be effective in preventing sexual assault (Brecklin, 2008; Senn et al., 2015; Vladutiu, Martin, \& Macy, 2011). But these programs would be prohibitively expensive to implement with all female soldiers, many of whom have extremely low risks of sexual assault victimization. However, our results suggest that interventions of this sort, if focused on women in the top ventile of predicted risk, would reach $33 \%$ to $63 \%$ of all those who would otherwise experience administratively reported and/or self-reported victimization along with some unknown proportion of those whose victimization currently goes unreported. Our models also suggest that substantial proportions of these high-risk women would go on to be victimized in the absence of a preventive intervention. These predicted victimization rates are sufficiently high $(6.7 \%$ in the model for administratively recorded victimization; $23.6 \%$ in the model for self-reported victimization) and the documented adverse psychological effects of victimization sufficiently strong (Turchik \& Wilson, 2010) to justify formal cost-benefit analyses of such an intervention (Foster \& Jones, 2006) taking competing risks (e.g., stigma, negative career consequences from identification as high risk) into consideration. If the results are positive, it would then make sense to invest in the research needed to develop a definitive consolidated set of models to predict overall sexual assault victimization and then use those models to select female soldiers for a pilot implementation and then, if successful, ongoing system-wide implementation of the intervention with high-risk women.

In considering these future directions, it should also be noted that even though we focused our model-building efforts on women, the AAS found that nearly half of all self-reported sexual assault victimizations occurred to men. This finding is broadly consistent with other surveys of military sexual assault (Morral et al., 2015b). We could have estimated a model for male administratively recorded victimization, but we know from the AAS and other previous surveys (Morral et al., 2015b) that only a very small proportion (probably no more than 5\%) of the sexual assault victimizations reported by male soldiers in surveys are reported to authorities. This means that selfreports of victimization would play a much more important role in developing consolidated models to predict overall sexual assault victimization for male than female soldiers. This was not possible in the AAS because of the low proportion of male respondents who reported sexual assault victimization (less than $0.2 \%$ ) even though these reports constitute a meaningful proportion of all self-reported sexual assaults due to the fact that $85 \%$ of soldiers are male. Given this low prevalence, it is unclear whether a consolidated prediction model for male sexual assault victimization could be developed that would have a sufficiently high concentration of risk to make it feasible to implement targeted high-risk preventive interventions cost-effectively. A much larger survey than the AAS would be needed to investigate this question with sufficient precision to draw a definitive conclusion.

Another important future direction should be to develop models to predict sexual assault perpetration. Although the AAS did not ask male soldiers about sexual assault perpetration, surveys of this sort have been carried out among college students (see reviews in Koss, 1993; Schewe, 2002) and to a lesser extent more general community samples of adult males (Abbey, Parkhill, BeShears, Clinton-Sherrod, \& Zawacki, 2006; Merrill, Thomsen, Gold, \& Milner, 2001; Widman, Olson, \& Bolen, 2013), although we are aware of no such survey among male military personnel. It would be useful to experiment with the feasibility of carrying out such a survey 
among male military personnel and, along the lines of the surveys on victimization carried out among female military personnel, to ask these men not only about selfreported perpetration but also about whether their $\operatorname{victim}(\mathrm{s})$ reported them to the military authorities. In addition, it would be useful to explore the possibility of developing a model of the administrative predictors of administratively recorded sexual assault perpetration. We are in the process of attempting to develop the latter type of model in our continued analyses of the HADS data. If successful, such a model could be useful in targeting high-risk preventive interventions, although evidence for the effectiveness of such interventions to reduce sexual assault perpetration is weaker than for interventions to reduce sexual assault victimization (Ellsberg et al., 2015).

\section{Acknowledgements}

The authors wish to thank Nate Galbreath, DoD's Sexual Assault and Prevention Office, and Stephen Axelrad, Booz Allen Hamilton, for helpful comments on two earlier versions of the article.

\section{Author Contributions}

A. E. Street, A. M. Zaslavsky, and R. C. Kessler developed the study concept. All authors contributed to the study design. E. D. Hill and M. V. Petukhova performed the data analyses under the supervision of R. C. Kessler, N. A. Sampson, A. J. Rosellini, and A. M. Zaslavsky. A. E. Street, R. C. Kessler, A. J. Rosellini, and J. Monahan drafted the paper, and the other coauthors provided several rounds of critical comments and helped prepare revisions. All authors approved the final version of the paper for submission.

\section{Declaration of Conflicting Interests}

M. B. Stein has been a consultant for Care Management Technologies; received payment for his editorial work from UpToDate, Depression and Anxiety, and Biological Psychiatry; and has been a paid consultant for Pfizer, Tonix, and Janssen. J. Monahan is co-owner of Classification of Violence Risk (COVR), Inc. R. C. Kessler has been a consultant for Johnson \& Johnson Wellness and Prevention and Sonofi-Aventis Groupe and has served on an advisory board for Lake Nona Institute. R. C. Kessler is a co-owner of DataStat, Inc. The other authors report no financial relationships with commercial interests.

\section{Funding}

The data analyzed in this report were collected as part of the Army STARRS. Army STARRS was sponsored by the Department of the Army and funded under cooperative agreement number U01MH087981 with the U.S. Department of Health and Human Services, National Institutes of Health, National Institute of Mental Health (NIH/NIMH). This research was conducted by Harvard Medical School and is funded by the DoD, Office of the Assistant Secretary for Defense for Health Affairs, Defense Health Program, awarded and administered by the U.S. Army Medical Research \& Materiel Command, at Fort Detrick,
Maryland, under contract numbers W81XWH-12-2-0113 and W81XWH-13-1-0037. A. E. Street's effort was supported with resources and the use of facilities at VA Boston Healthcare System, Boston, Massachusetts.

\section{Role of the Funder/Sponsor}

The sponsors had no role in the design and conduct of the study; collection, management, analysis, and interpretation of the data; preparation, review, or approval of the manuscript; and decision to submit the manuscript for publication. Although a draft of this manuscript was submitted to the DoD, the Department of the Army, and NIMH for review and comment prior to submission, this was with the understanding that comments would be no more than advisory.

\section{Disclaimer}

The views, opinions, and/or findings contained in this research are those of the authors and do not necessarily reflect the views of the funding agencies and should not be construed as an official DoD/Army position, policy, or decision unless so designated by other documentation. No official endorsement should be made.

\section{References}

Abbey, A., Parkhill, M. R., BeShears, R., Clinton-Sherrod, A. M., \& Zawacki, T. (2006). Cross-sectional predictors of sexual assault perpetration in a community sample of single African American and Caucasian men. Aggressive Behavior, 32, 54-67. doi:10.1002/ab.20107

Alho, J. M. (1990). Logistic regression in capture-recapture models. Biometrics, 46, 623-635.

Alho, J. M., Mulry, M. H., Wurdeman, K., \& Kim, J. (1993). Estimating heterogeneity in the probabilities of enumeration for dual-system estimation. Journal of the American Statistical Association, 88(1), 130-136.

American Association for Public Opinion Research. (2009). Standard definitions: Final dispositions of case codes and outcome rates for surveys. Retrieved from http:// www.aapor.org/AAPORKentico/Communications/AAPORJournals/Standard-Definitions.aspx

Brecklin, L. R. (2008). Evaluation outcomes of self-defense training for women: A review. Aggression and Violent Behavior, 13, 60-76.

Breiman, L., Cutler, A., Liaw, A., \& Wiener, M. (2012). Package "randomForest": Breiman and Cutler's random forests for classification and regression (Version 4.6-7). Retrieved from http://cran.r-project.org/web/packages/randomForest/randomForest.pdf

Campbell, J. C., Webster, D. W., \& Glass, N. (2009). The danger assessment: Validation of a lethality risk assessment instrument for intimate partner femicide. Journal of Interpersonal Violence, 24, 653-674.

Castro, C. A., Kintzle, S., Schuyler, A. C., Lucas, C. L., \& Warner, C. H. (2015). Sexual assault in the military. Current Psychiatry Reports, 17, 54. doi:10.1007/s11920-015-0596-7

Chan, K. L. (2012). Predicting the risk of intimate partner violence: The Chinese risk assessment tool for victims. Journal of Family Violence, 27, 157-164. 
Cook, S. L., Gidycz, C. A., Koss, M. P., \& Murphy, M. (2011). Emerging issues in the measurement of rape victimization [review]. Violence Against Women, 17, 201-218. doi:10 $.1177 / 1077801210397741$

Coxell, A., King, M., Mezey, G., \& Gordon, D. (1999). Lifetime prevalence, characteristics, and associated problems of non-consensual sex in men: Cross sectional survey. British Medical Journal, 318, 846-850.

DeGue, S., Simon, T. R., Basile, K. C., Yee, S. L., Lang, K., \& Spivak, H. (2012). Moving forward by looking back: Reflecting on a decade of CDC's work in sexual violence prevention, 2000-2010 [review]. Journal of Women's Health, 21, 1211-1218. doi:10.1089/jwh.2012.3973

Ellsberg, M., Arango, D. J., Morton, M., Gennari, F., Kiplesund, S., Contreras, M., \& Watts, C. (2015). Prevention of violence against women and girls: What does the evidence say? [research support, non-U.S. government review]. Lancet, 385, 1555-1566. doi:10.1016/S0140-6736(14)61703-7

Fazel, S., Singh, J. P., Doll, H., \& Grann, M. (2012). Use of risk assessment instruments to predict violence and antisocial behaviour in 73 samples involving 24827 people: Systematic review and meta-analysis. British Medical Journal, 345, e4692.

Fengler, J., \& Winkel, F. W. (2014). The development of an (ODARA-based) actuarial screening version of the Danger Assessment Inventory (DAI): A traumatic diversityapproach and some follow up evidence. In P. Schaefer \& E. Weitekamp (Eds.), Establishing victimology (pp. 151-169). Niederrhein, Germany: Niederrhein University Press.

Fisher, B. S. (2009). The effects of survey question wording on rape estimates: Evidence from a quasi-experimental design [research support, U.S. government, non-public health service]. Violence Against Women, 15, 133-147. doi:10. $1177 / 1077801208329391$

Foster, E. M., \& Jones, D. (2006). Can a costly intervention be cost-effective? An analysis of violence prevention. Archives of General Psychiatry, 63, 1284-1291.

Franklin, C. A., Franklin, T. W., Nobles, M. R., \& Kercher, G. (2011). Risk factors associated with women's victimization. Huntsville, TX: Crime Victims' Institute, Criminal Justice Center, Sam Houston State University.

Friedman, J., Hastie, T., \& Tibshirani, R. (2010). Regularization paths for generalized linear models via coordinate descent. Journal of Statistical Software, 33, 1-22.

Golubnitschaja, O., \& Costigliola, V. (2012). General report \& recommendations in predictive, preventive and personalised medicine 2012: White paper of the European Association for Predictive, Preventive and Personalised Medicine. EPMA Journal, 3, 14.

Harned, M. S., Ormerod, A. J., Palmieri, P. A., Collinsworth, L. L., \& Reed, M. (2002). Sexual assault and other types of sexual harassment by workplace personnel: A comparison of antecedents and consequences. Journal of Occupational and Health Psychology, 7, 174-188.

Harris, A., Phenix, A., Hanson, R. K., \& Thornton, D. (2003). STATIC-99 coding rules revised. Ottawa, Canada: Department of the Solicitor General.

Heeringa, S. G., Gebler, N., Colpe, L. J., Fullerton, C. S., Hwang, I., Kessler, R. C., . . . Ursano, R. J. (2013). Field procedures in the Army Study to Assess Risk and Resilience in
Servicemembers (Army STARRS). International Journal of Methods in Psychiatric Research, 22, 276-287.

Hook, E. B., Hsia, M. S., \& Regal, R. R. (2012). Accuracy of capture-recapture estimates of prevalence. Epidemiologic Methods, 1, 1-11.

Jewkes, R., Sen, P., \& Garcia-Moreno, C. (2002). Sexual violence. In E. G. Krug (Ed.), World report on violence and bealth (Vol. 1, pp. 213-239). Geneva, Switzerland: World Health Organization.

Kessler, R. C., Colpe, L. J., Fullerton, C. S., Gebler, N., Naifeh, J. A., Nock, M. K., . . Heeringa, S. G. (2013). Design of the Army Study to Assess Risk and Resilience in Servicemembers (Army STARRS). International Journal of Methods in Pyschiatric Research, 22, 267-275. doi:10.1002/mpr.1401

Kessler, R. C., Heeringa, S. G., Colpe, L. J., Fullerton, C. S., Gebler, N., Hwang, I., . . . Ursano, R. J. (2013). Response bias, weighting adjustments, and design effects in the Army Study to Assess Risk and Resilience in Servicemembers (Army STARRS). International Journal of Methods in Psychiatric Research, 22, 288-302.

Kessler, R. C., Warner, C. H., Ivany, C., Petukhova, M. V., Rose, S., Bromet, E. J., . . . Ursano, R. J. (2015). Predicting suicides after psychiatric hospitalization in US Army soldiers: The Army Study to Assess Risk and Resilience in Servicemembers (Army STARRS). JAMA Psychiatry, 72, 49-57.

Kimerling, R., Gima, K., Smith, M. W., Street, A., \& Frayne, S. (2007). The Veterans Health Administration and military sexual trauma. American Journal of Public Health, 97, 2160-2166.

Koss, M. P. (1993). Rape. Scope, impact, interventions, and public policy responses [research support, U.S. government, public health service]. The American Psychologist, 48, 1062-1069.

Krebs, C. P., Lindquist, C. H., Warner, T. D., Fisher, B. S., \& Martin, S. L. (2007). The Campus Sexual Assault (CSA) Study (221153). Washington, DC: National Institute of Justice, U.S. Department of Justice.

Kruttschnitt, C., Kalsbeek, W. D., \& House, C. C. (2014). Estimating the incidence of rape and sexual assault. Retrieved from http://www.nap.edu/read/18605/chapter/1

Lalor, K., \& McElvaney, R. (2010). Child sexual abuse, links to later sexual exploitation/high-risk sexual behavior, and prevention/treatment programs [research support, non-U.S. government review]. Trauma, Violence \& Abuse, 11, 159177. doi:10.1177/1524838010378299

Leardmann, C. A., Pietrucha, A., Magruder, K. M., Smith, B., Murdoch, M., Jacobson, I. G., . . . Smith, T. C. (2013). Combat deployment is associated with sexual harassment or sexual assault in a large, female military cohort [research support, U.S. government, non-public health service]. Women's Health Issues: Official Publication of the Jacobs Institute of Women's Health, 23, e215-e223. doi:10.1016/j. whi.2013.05.002

Lisak, D., \& Miller, P. M. (2002). Repeat rape and multiple offending among undetected rapists. Violence and Victims, $17,73-84$.

Littleton, H., Axsom, D., \& Grills-Taquechel, A. (2009). Sexual assault victims' acknowledgement status and revictimization risk. Psychology of Women Quarterly, 33, 34-42. doi:10.1111/j.1471-6402.2008.01472.x 
Littleton, H., \& Ullman, S. E. (2013). PTSD symptomatology and hazardous drinking as risk factors for sexual assault revictimization: Examination in European American and African American women. Journal of Traumatic Stress, 26, 345-353.

Mengeling, M. A., Booth, B. M., Torner, J. C., \& Sadler, A. G. (2014). Reporting sexual assault in the military: Who reports and why most servicewomen don't. American Journal of Preventive Medicine, 47, 17-25.

Merrill, L. L., Newell, C. E., Thomsen, C. J., Gold, S. R., Milner, J. S., Koss, M. P., \& Rosswork, S. G. (1999). Childhood abuse and sexual revictimization in a female Navy recruit sample. Journal of Traumatic Stress, 12, 211-225.

Merrill, L. L., Thomsen, C. J., Gold, S. R., \& Milner, J. S. (2001). Childhood abuse and premilitary sexual assault in male Navy recruits [research support, U.S. government, nonpublic health service]. Journal of Consulting and Clinical Psychology, 69, 252-261.

Messman-Moore, T. L., \& Long, P. J. (2000). Child sexual abuse and revictimization in the form of adult sexual abuse, adult physical abuse, and adult psychological maltreatment. Journal of Interpersonal Violence, 15, 489-502.

Morral, A. R., Gore, K. L., Schell, T. L., Bicksler, B., Farris, C., Ghosh-Dastidar, B., ... Williams, K. M. (2015a). Sexual assault and sexual harassment in the U.S. military: Annex to Volume 2. Tabular results from the 2014 RAND Military Workplace Study for Department of Defense Service Members. Retrieved from http://www.rand.org/pubs/ research_reports/RR870z3.html

Morral, A. R., Gore, K. L., Schell, T. L., Bicksler, B., Farris, C., Ghosh-Dastidar, B., . . . Williams, K. M. (2015b). Sexual assault and sexual harassment in the U.S. military: Volume 2. Estimates for Department of Defense Service Members from the 2014 RAND Military Workplace Study. Retrieved from http://www.rand.org/pubs/research_reports/RR870z2.html

Morral, A. R., Gore, K. L., Schell, T. L., Jaycox, L. H., GhoshDastidar, B., Farris, C., . . . Williams, K. M. (2014). Sexual assault and sexual harassment in the U.S. military: Topline estimates for active-duty service members from the 2014 RAND Military Workplace Study. Santa Monica, CA: National Defense Research Institute.

Niebuhr, D. W., Gubata, M. E., Oetting, A. A., Weber, N. S., Feng, X., \& Cowan, D. N. (2013). Personality Assessment Questionnaire as a pre-accession screen for risk of mental disorders and early attrition in U. S. Army recruits [research support, U.S. government, non-public health service]. Psychological Services, 10, 378-385. doi:10.1037/a0032783

Orcutt, H. K., Erickson, D. J., \& Wolfe, J. (2002). A prospective analysis of trauma exposure: The mediating role of PTSD symptomatology [research support, U.S. government, non-public health service]. Journal of Traumatic Stress, 15, 259-266. doi:10.1023/A:1015215630493

Quinsey, V. L., Harris, G. T., Rice, M. E., \& Cormier, C. A. (2006). Violent offenders: Appraising and managing risk (2nd ed.). Washington, DC: American Psychological Association.

Risser, H. J., Hetzel-Riggin, M. D., Thomsen, C. J., \& McCanne, T. R. (2006). PTSD as a mediator of sexual revictimization: The role of reexperiencing, avoidance, and arousal symptoms. Journal of Traumatic Stress, 19, 687-698. doi:10.1002/ jts. 20156
Rock, L. M. (2013). 2012 Workplace and Gender Relations Survey of Active Duty Members. Washington, DC: Defense Technical Information Center. Retrieved from http:// www.sapr.mil/public/docs/research/2012_Workplace_ and_Gender_Relations_Survey_of_Active_Duty_MembersSurvey_Note_and_Briefing.pdf

Rosellini, A. J., Monahan, J., Street, A. E., Heeringa, S. G., Hill, E. D., Petukhova, M., . . Kessler, R. C. (2016). Predicting non-familial major physical violent crime perpetration in the US Army from administrative data. Psychological Medicine, 46, 303-316.

Sadler, A. G., Booth, B. M., Cook, B. L., \& Doebbeling, B. N. (2003). Factors associated with women's risk of rape in the military environment. American Journal of Industrial Medicine, 43, 262-273.

SAS Institute Inc. (2010). SAS/STATR Software (Version 9.3 for Unix). Cary, NC: SAS Institute Inc.

Schewe, P. A. (2002). Preventing violence in relationships: Interventions across the life span. Washington, DC: American Psychological Association.

Schlesselman, J. J. (1982). Case-control studies: Design, conduct, analysis. New York: Oxford University Press.

Schry, A. R., \& White, S. W. (2013). Sexual assertiveness mediates the effect of social interaction anxiety on sexual victimization risk among college women. Behavior Therapy, 44, 125-136. doi:10.1016/j.beth.2012.09.001

Secretary of Defense. (2014). 2014-2016 sexual assault prevention strategy. Retrieved from http://www.sapr.mil/index.php/ prevention/prevention-strategy

Sekar, C. C., \& Deming, W. E. (1949). On a method of estimating birth and death rates and the extent of registration. Journal of the American Statistical Association, 44, 101-115.

Senn, C. Y., Eliasziw, M., Barata, P. C., Thurston, W. E., NewbyClark, I. R., Radtke, H. L., \& Hobden, K. L. (2015). Efficacy of a sexual assault resistance program for university women. The New England Journal of Medicine, 372, 2326-2335.

Street, A. E., Stafford, J., Mahan, C. M., \& Hendricks, A. (2008). Sexual harassment and assault experienced by reservists during military service: Prevalence and health correlates [historical article research support, U.S. government, nonpublic health service]. Journal of Rebabilitation Research and Development, 45, 409-419.

Testa, M., VanZile-Tamsen, C., \& Livingston, J. A. (2007). Prospective prediction of women's sexual victimization by intimate and nonintimate male perpetrators. Journal of Consulting and Clinical Psychology, 75, 52-60.

Tewksbury, R., \& Mustaine, E. E. (2001). Lifestyle factors associated with the sexual assault of men: A routine activity theory analysis. Journal of Men's Studies, 9, 153-182.

Thornton, D., Mann, R., Webster, S., Blud, L., Travers, R., Friendship, C., \& Erikson, M. (2003). Distinguishing and combining risks for sexual and violent recidivism [validation studies]. Annals of the New York Academy of Sciences, 989, 225-235, discussion 236-246.

Turchik, J. A., \& Wilson, S. M. (2010). Sexual assault in the U.S. military: A review of the literature and recommendations for the future. Aggression and Violent Behavior, 15, 267-277.

U.S. Department of Justice. (2009). National Corrections Reporting Program, 2009 (ICPSR 30799). Ann Arbor, MI: National Achive of Criminal Justice Data. 
Ullman, S. E. (2003). A critical review of field studies on the link of alcohol and adult sexual assault in women. Aggression and Violent Behavior, 8, 471-486. doi:http://dx.doi.org/ 10.1016/S1359-1789(03)00032-6

Ursano, R. J., Colpe, L. J., Heeringa, S. G., Kessler, R. C., Schoenbaum, M., \& Stein, M. B. (2014). The Army Study to Assess Risk and Resilience in Servicemembers (Army STARRS). Psychiatry, 77, 107-119.

Vladutiu, C. J., Martin, S. L., \& Macy, R. J. (2011). College- or university-based sexual assault prevention programs: A review of program outcomes, characteristics, and recommendations [review]. Trauma, Violence \& Abuse, 12, 67-86.

Whittington, R., Hockenhull, J. C., McGuire, J., Leitner, M., Barr, W., Cherry, M. G., . . . Dickson, R. (2013). A systematic review of risk assessment strategies for populations at high risk of engaging in violent behaviour: Update 2002-8. Health Technology Assessment, 17, i-xiv, 1-128.

Widman, L., Olson, M. A., \& Bolen, R. M. (2013). Self-reported sexual assault in convicted sex offenders and community men [comparative study]. Journal of Interpersonal Violence, 28, 1519-1536. doi:10.1177/0886260512468237
Willett, J. B., \& Singer, J. D. (1993). Investigating onset, cessation, relapse, and recovery: Why you should, and how you can, use discrete-time survival analysis to examine event occurrence. Journal of Consulting and Clinical Psychology, 61, 952-965.

Wolitzky-Taylor, K. B., Resnick, H. S., McCauley, J. L., Amstadter, A. B., Kilpatrick, D. G., \& Ruggiero, K. J. (2011). Is reporting of rape on the rise? A comparison of women with reported versus unreported rape experiences in the National Women's Study-Replication [comparative study research support, U.S. government, non-public health service]. Journal of Interpersonal Violence, 26, 807-832. doi:10.1177/ 0886260510365869

Wolter, K. M. (1985). Introduction to variance estimation. New York: Springer-Verlag.

Yang, M., Wong, S. C., \& Coid, J. (2010). The efficacy of violence prediction: A meta-analytic comparison of nine risk assessment tools. Psychological Bulletin, 136, 740-767.

Zou, H., \& Hastie, T. (2005). Regularization and variable selection via the elastic net. Journal of the Royal Statistical Society: Series B, 67, 301-320. 